\title{
Lanthanide Tags for Site-Specific Ligation to an Unnatural Amino Acid and Generation of Pseudocontact Shifts in Proteins
}

\author{
Choy Theng Loh, ${ }^{\dagger}$ Kiyoshi Ozawa, ${ }^{\S}$ Kellie L. Tuck, ${ }^{\ddagger}$ Nicholas Barlow," Thomas Huber, ${ }^{\dagger}$ \\ Gottfried Otting, ${ }^{*} \dagger$ and Bim Graham*, ${ }^{*}$ \\ ${ }^{\dagger}$ Research School of Chemistry, Australian National University, Canberra, ACT 0200, Australia \\ ${ }^{\S}$ School of Chemistry, University of Wollongong, NSW 2522, Australia \\ ${ }^{\ddagger}$ School of Chemistry, Monash University, Clayton, VIC 3800, Australia \\ ${ }$ Medicinal Chemistry, Monash Institute of Pharmaceutical Sciences, Parkville, VIC 3052, Australia
}

\section{Supporting Information}

ABSTRACT: Pseudocontact shifts (PCS) from paramagnetic lanthanide ions present powerful long-range structural restraints for structural biology by NMR spectroscopy, but site-specific tagging of proteins with lanthanides remains a challenge, as most of the available lanthanide tags require proteins with single cysteine residues. We show that cyclenbased paramagnetic lanthanide tags can be attached to proteins in a site-specific manner by $\mathrm{Cu}(\mathrm{I})$-catalyzed azide-alkyne cycloaddition to a genetically encoded $p$-azido-L-phenylalanine residue with a tether that proved sufficiently short and rigid for the observation of PCSs in several proteins. Despite the sterically demanding conditions associated with bulky tags and reactions close to the protein surface, ligation yields consistently above $50 \%$ and approaching $100 \%$ were obtained with the help of the $\mathrm{Cu}(\mathrm{I})$-stabilizing ligand BTTAA. The yields were high independent of the presence of cysteine residues, thereby avoiding the need for cysteine mutations associated with conventional lanthanide-tagging strategies.

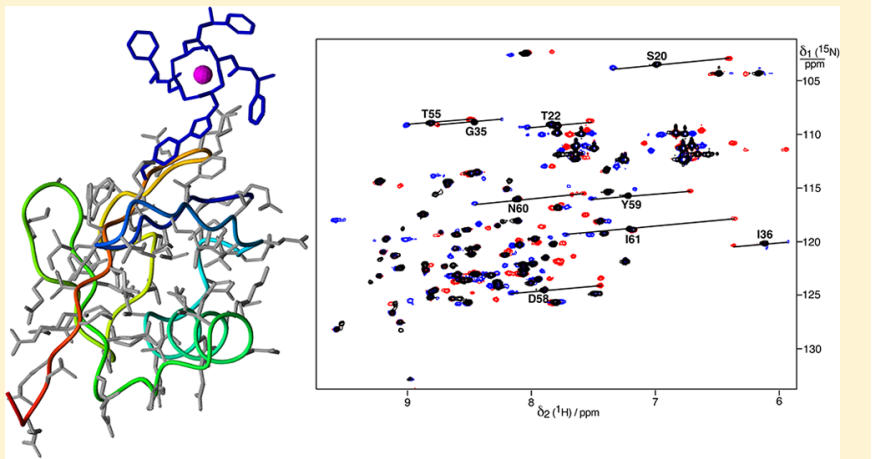

\section{INTRODUCTION}

Pseudocontact shifts (PCSs) induced by paramagnetic lanthanide ions provide an exceptionally rich source of information for protein structural biology by nuclear magnetic resonance (NMR) spectroscopy in solution. ${ }^{1}$ In particular, the long-range nature $(>40 \AA)^{2}$ of the PCSs opens outstanding opportunities for 3D structure determinations of proteins, ${ }^{3}$ and protein-protein $^{4-6}$ and protein-ligand ${ }^{7-9}$ complexes. PCSs are easily measured as the difference in chemical shifts between samples carrying a paramagnetic or a diamagnetic metal ion. To obtain useful PCSs, however, the lanthanide must be sitespecifically tied to the protein. In addition, the lanthanide must be attached quite rigidly, as the PCSs are governed by the magnetic susceptibility anisotropy tensor $(\Delta \chi)$ of the paramagnetic metal ion, which generates positive or negative PCSs depending on the position of the nuclear spin relative to the $\Delta \chi$ tensor. Motions of the tag relative to the protein can easily average the PCSs to zero.

The interest in lanthanide-induced PCSs sparked a large effort to find suitable lanthanide binding tags. ${ }^{10-14}$ Most of the tags depend on the availability of single cysteine residues in the target protein for site-specific reaction. ${ }^{15-31}$ This is a severe limitation, especially for large proteins that usually contain several cysteine residues, as the mutation of natural cysteine 
A

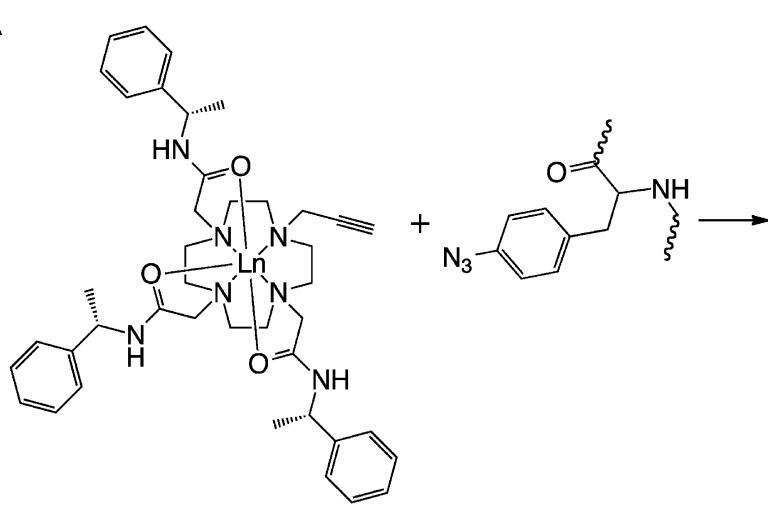

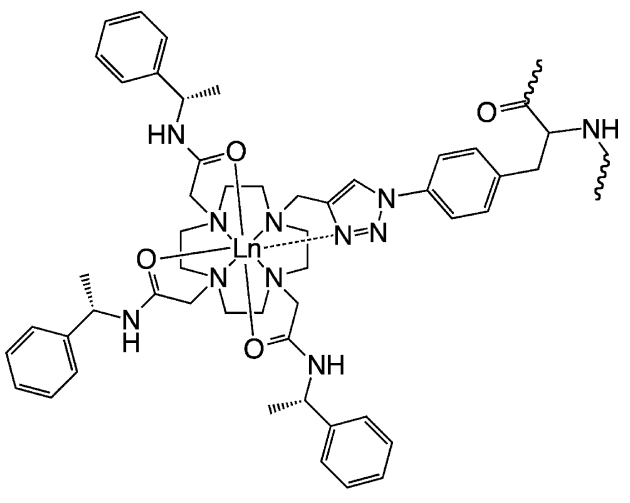

B

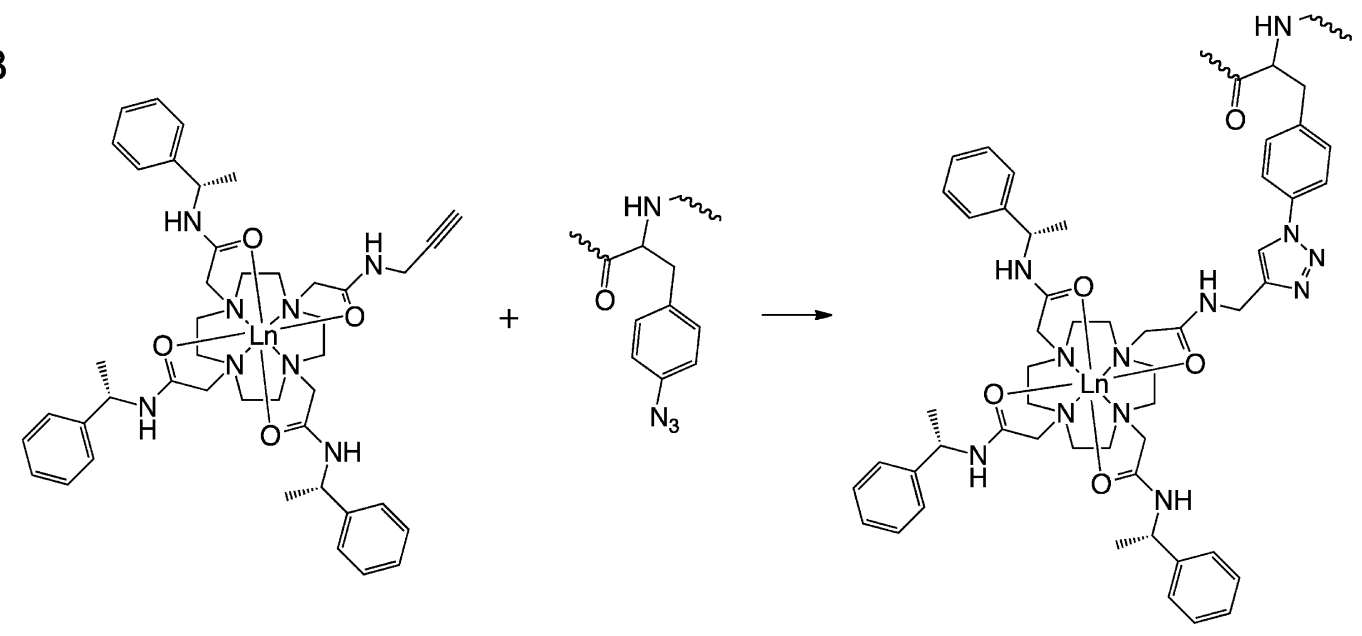

Figure 1. Reaction scheme of the $\mathrm{C} 3$ and $\mathrm{C} 4$ tags with a $p$-azido-L-phenylalanine (AzF) residue within a protein using $\mathrm{Cu}(\mathrm{I})$-catalyzed click chemistry. The structural rigidity of the lanthanide complex and the near-coplanarity of the phenylene and triazole rings arising from conjugated double bonds result in relatively few degrees of conformational freedom for the tethers linking the amino acid and the lanthanide. (A) Reaction of the $\mathrm{C} 3 \mathrm{tag}$. It is not clear whether the triazole coordinates the lanthanide in the reaction product. In the present work, this coordination was not assumed to be present. (B) Reaction of the $\mathrm{C} 4 \mathrm{tag}$. The tether between amino acid and lanthanide is longer than in the case of the $\mathrm{C} 3 \mathrm{tag}$, but the number of freely rotatable bonds is similar.

enantiomeric form of the lanthanide chelate. Related tags ( $\mathrm{C} 1$ and $\mathrm{C} 2$ ) have been designed previously for attachment to cysteine residues and were shown to generate good PCSs. ${ }^{24,40}$ Although the tethers between lanthanide and protein backbone are longer in the case of the new tags presented here, the resulting moieties proved sufficiently rigid to produce sizable PCSs. Compared to the widely studied attachment of fluorescent tags (e.g., ref 41), the present application was challenging because consistently high reaction yields are required for interpretable NMR spectra, and the requirement of short tethers meant that the reaction had to proceed in a sterically crowded environment near the protein surface.

\section{EXPERIMENTAL PROCEDURES}

Protein Synthesis. The proteins containing AzF were produced in vivo in E. coli using the published $\mathrm{pEVOL}$ vector with the aminoacyl-tRNA synthetase for AzF (AzF-RS). ${ }^{39,42}$ The protein genes, containing amber stop codons for the insertion of $\mathrm{AzF}$, were cloned into pETMCSI T7 vectors. ${ }^{43}$ Both plasmids were transformed into E. coli BL21(DE3) grown at $37^{\circ} \mathrm{C}$ in the presence of $100 \mu \mathrm{g} / \mathrm{mL}$ ampicillin and $33 \mu \mathrm{g} /$ $\mathrm{mL}$ chloramphenicol.

Human ubiquitin was expressed with a C-terminal $\mathrm{His}_{6} \mathrm{tag}$ and an amber stop codon to replace residue Glu18 or Thr66 with AzF. Ten milliliters of an overnight culture was used to inoculate $1 \mathrm{~L}$ Luria-Bertani medium supplemented with $0.02 \%$ arabinose. After growing to an $\mathrm{OD}_{600}$ of $1.5-2.0$, the cultures were changed to $500 \mathrm{~mL}$ minimal media for ${ }^{15} \mathrm{~N}$-labeling, containing $0.5 \mathrm{~g} / \mathrm{L}{ }^{15} \mathrm{~N}$-ammonium chloride, $0.02 \%$ arabinose, and $1 \mathrm{mM}$ p-azido-L-phenylalanine. ${ }^{44}$ Following incubation at $37{ }^{\circ} \mathrm{C}$ for another $1-2 \mathrm{~h}$, overexpression was induced with 1 $\mathrm{mM}$ isopropyl- $\beta$-D-thiogalactopyranoside (IPTG). The cultures were harvested after overnight expression $(\sim 16 \mathrm{~h})$ at $25^{\circ} \mathrm{C}$ by centrifugation. Pellets were resuspended in buffer A $(20 \mathrm{mM}$ HEPES buffer, $\mathrm{pH} 7.5,150 \mathrm{mM}$ sodium chloride, $5 \%$ glycerol, $20 \mathrm{mM}$ imidazole), and the cells were lysed using a French press at $12000 \mathrm{psi}$. The cell lysates were centrifuged for $1 \mathrm{~h}$ at $34000 \mathrm{~g}$. The supernatant was loaded onto a $5 \mathrm{~mL} \mathrm{Ni-NTA}$ column (GE Healthcare, USA) and the protein was eluted with buffer B (same as buffer A but containing $500 \mathrm{mM}$ imidazole). The fractions were analyzed by $15 \%$ SDS-PAGE. Fractions containing protein were pooled and dialyzed against click buffer (50 mM HEPES, pH 7.5) at $4{ }^{\circ} \mathrm{C}$. Finally, the samples were concentrated using an Amicon ultrafiltration centrifugal tube with a molecular weight cutoff (MWCO) of $3 \mathrm{kDa}$.

The gene of ubiquitin Glu18AzF without $\mathrm{His}_{6}$ tag was expressed as described above. The supernatant from the cell lysate was loaded onto an SP Sepharose column $(30 \mathrm{~mL})$ 


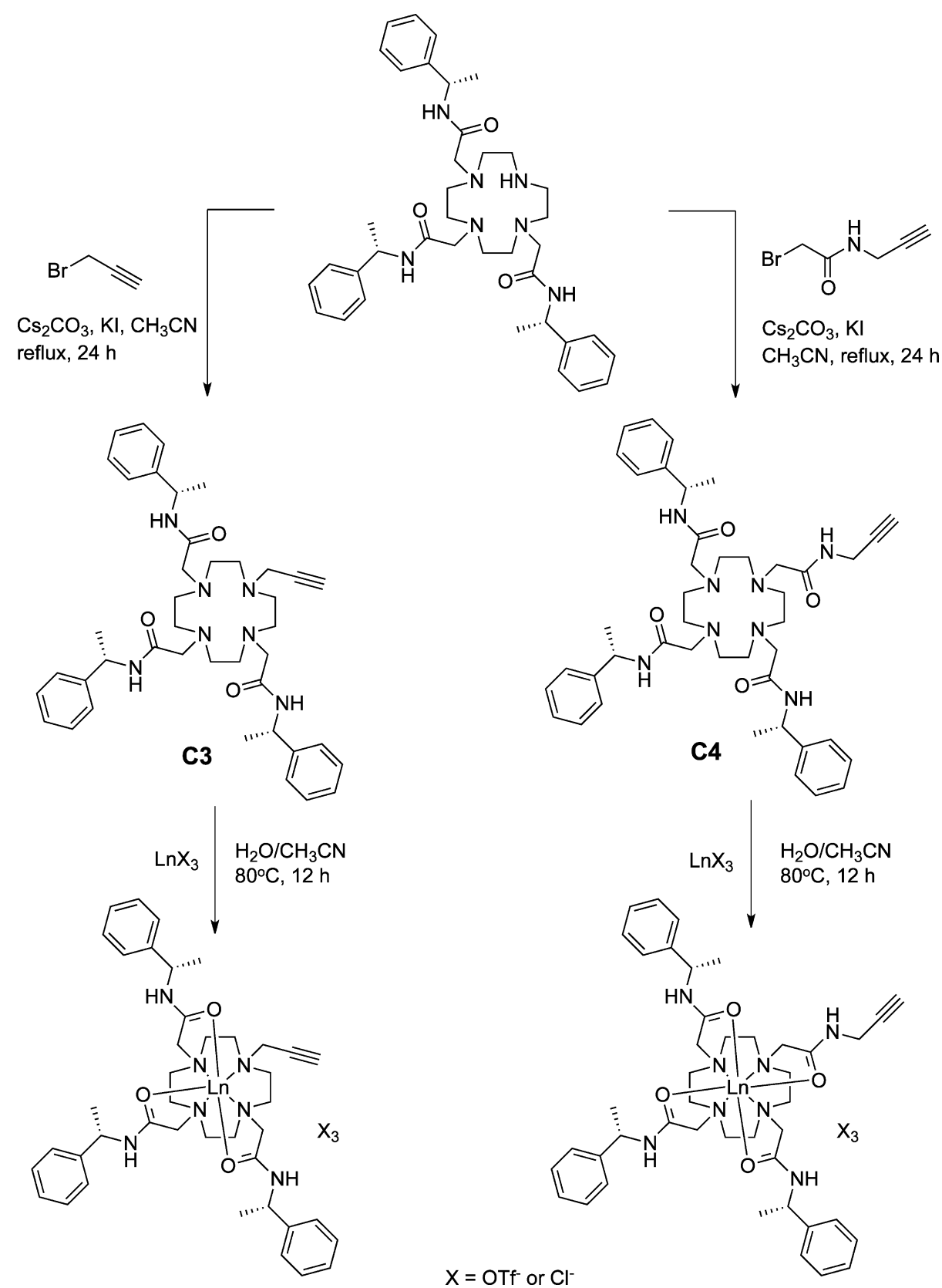

Figure 2. Synthesis of the C3 and C4 tags and their lanthanide complexes.

equilibrated with buffer C (20 mM MES, pH 6.8). The column was washed with buffer $\mathrm{C}$ to remove unbound proteins, and the bound proteins were eluted with a linear gradient of increasing sodium chloride $(0-1 \mathrm{M})$. Fractions were analyzed by $15 \%$ SDS-PAGE, and protein fractions were pooled and dialyzed against click buffer.

The expression and purification protocols of the intracellular domain of the p75 neurotrophin receptor with C-terminal $\mathrm{His}_{6}$ tag (p75 ICD) and an amber stop codon at Lys350 and of $S$. aureus sortase A with $\mathrm{C}$-terminal $\mathrm{His}_{6}$ tag and amber stop codons at Gln55 and Ser99 were the same as those described above for the ubiquitin mutants with $\mathrm{C}$-terminal $\mathrm{His}_{6}$ tag, except that the click buffer also contained $1 \mathrm{mM}$ DTT. Total protein yields for each protein from $500 \mathrm{~mL}$ culture medium were as follows: $87 \mathrm{mg}$ ubiquitin Glu18AzF, $55 \mathrm{mg}$ ubiquitin Glu18AzF with C-terminal $\mathrm{His}_{6}$ tag, $72 \mathrm{mg}$ ubiquitin Thr66AzF with C-terminal $\mathrm{His}_{6}$ tag, $20 \mathrm{mg}$ p75 ICD Lys55AzF, $34 \mathrm{mg}$ sortase A Gln55AzF, and $48 \mathrm{mg}$ sortase A Ser99AzF.

Tag Synthesis. 2,2',2"'-(10-(Prop-2-ynyl)-1,4,7,10-tetraazacyclododecane-1,4,7-triyl) tris $(N-((S)-1$ phenylethyl)acetamide) (C3). The synthetic route to the $\mathrm{C} 3$ and C4 tags is shown in Figure 2. A mixture containing 1,4,7tris $((S)$-1-(1-phenyl)ethylcarbomylmethyl)-1,4,7,10-tetraazacyclododecane $^{24}(1.000 \mathrm{~g}, 1.53 \mathrm{mmol})$, propargyl bromide $(0.362$ $\mathrm{g}, 3.04 \mathrm{mmol}), \mathrm{Cs}_{2} \mathrm{CO}_{3}(1.027 \mathrm{~g}, 3.15 \mathrm{mmol})$, and $\mathrm{KI}(0.1 \mathrm{~g}$, $0.6 \mathrm{mmol})$ in acetonitrile $(50 \mathrm{~mL})$ was heated to reflux for $24 \mathrm{~h}$. After cooling to room temperature, inorganic salts were removed by filtration and the solvent removed under reduced pressure. Purification of the remaining oily brown residue by flash chromatography $(0 \rightarrow 10 \% \mathrm{MeOH}$ in DCM) afforded the product as a pale yellow oil $(0.735 \mathrm{~g}, 69 \%) .{ }^{1} \mathrm{H}$ NMR (400 $\left.\mathrm{MHz}, \mathrm{CHCl}_{3} / \mathrm{D}_{2} \mathrm{O}\right) \delta$ 7.37-7.11 (complex, $\left.15 \mathrm{H}\right), 5.04(\mathrm{q}, J=$ $6.8 \mathrm{~Hz}, 1 \mathrm{H}), 4.99(\mathrm{q}, J=7.2 \mathrm{~Hz}, 1 \mathrm{H}), 4.88(\mathrm{q}, J=6.8 \mathrm{~Hz}, 1 \mathrm{H})$, 
4.05, $4.00(\mathrm{ABq}, J=15.8 \mathrm{~Hz}, 1 \mathrm{H}), 3.55(\mathrm{~m}, 1 \mathrm{H}), 3.23,3.14$ $(\mathrm{ABq}, J=14.8 \mathrm{~Hz}, 2 \mathrm{H}), 3.09-2.68$ (complex, 4H), 2.66-2.03 (complex, 14H), $2.02(\mathrm{t}, J=2.0 \mathrm{~Hz}, 1 \mathrm{H}), 1.92(\mathrm{~d}, J=13.3 \mathrm{~Hz}$, 1H), $1.48-1.39$ (complex, 9H). ${ }^{13} \mathrm{C}$ NMR (100 MHz, $\mathrm{CHCl}_{3}$ ) $\delta 170.9,170.5,170.4,144.4,143.6,143.5,128.6,128.6,128.5$, $128.4,127.4,127.3,127.0,126.5,126.4,126.2,126.1,77.2,62.0$, 58.5, 57.4, 51.3, 50.8, 50.4, 49.8, 49.47, 49.44, 48.4, 42.3, 22.2, 22.1, 21.8. HRMS (ESI) $m / z$ calcd for $[\mathrm{M}+\mathrm{H}]^{+} \mathrm{C}_{41} \mathrm{H}_{56} \mathrm{~N}_{7} \mathrm{O}_{3}$ : 694.4439, found: 694.4424 .

$2,2^{\prime}, 2^{\prime \prime}-(10-(2-0 \times 0-2-(p r o p-2-y n y l a m i n o) e t h y l)-$ 1,4,7,10-tetraazacyclododecane-1,4,7-triyl)tris(N-((S)-1phenylethyl)acetamide) (C4). The procedure described above was followed using 2-bromo- $N$-(prop-2-ynyl)acetamide $(0.542 \mathrm{~g}, 3.08 \mathrm{mmol})$ in place of propargyl bromide. The product was obtained as a pale yellow oil $(0.835 \mathrm{~g}, 73 \%) .{ }^{1} \mathrm{H}$ NMR (400 MHz, $\mathrm{CHCl}_{3} / d_{6}$-acetone $\left./ \mathrm{D}_{2} \mathrm{O}\right) \quad \delta$ 7.27-7.15 (complex, 12H), 7.14-7.06 (complex, 3H), 4.95 (q, $J=7.2$ $\mathrm{Hz}, 1 \mathrm{H}$ ), 4.87 (q, $J=7.0 \mathrm{~Hz}, 2 \mathrm{H}), 3.89$ (A of ABX, $J=17.3 \mathrm{~Hz}$, $1 \mathrm{H}), 3.76$ (B of $\mathrm{ABX}, J=17.3,2.2 \mathrm{~Hz}, 1 \mathrm{H}), 3.26(\mathrm{~d}, J=14.4$ $\mathrm{Hz}, 1 \mathrm{H}), 3.92-2.17$ (complex, 17H), 2.33 (t, $J=2.0 \mathrm{~Hz}, 1 \mathrm{H})$, 2.16-1.80 (complex, 6H), 1.40-1.32 (complex, 9H). ${ }^{13} \mathrm{C}$ NMR (100 MHz, $\mathrm{CHCl}_{3} / d_{6}$-acetone) $\delta 170.3,170.1,169.8$, 143.8 , 143.6, 127.7, 127.6, 126.20, 126.15, 125.46, 125.41, 77.2, $76.7,70.3,56.2,56.1,56.0,50.5,50.3,50.2,48.8,48.5,48.3$, $27.9,20.95,20.91$. HRMS (ESI) $\mathrm{m} / z$ calcd for $[\mathrm{M}+\mathrm{H}]^{+}$ $\mathrm{C}_{43} \mathrm{H}_{59} \mathrm{~N}_{8} \mathrm{O}_{4}$ : 751.4654 , found: 751.4620 .

Formation of Metal Complexes. As binding of lanthanides to cyclen derivatives is extremely slow and requires heating, we did not attempt to exchange the metal ion from tagged protein samples. To produce protein samples with different lanthanides, the $\mathrm{C} 3$ and $\mathrm{C} 4$ tags were complexed with different paramagnetic and diamagnetic ions $\left(\mathrm{Tb}^{3+}, \mathrm{Tm}^{3+}, \mathrm{Y}^{3+}\right)$ by heating the tags in 1:1 (v/v) acetonitrile/water with a molar equivalent of the respective metal triflate or chloride salts for 12 $\mathrm{h}$ at $80{ }^{\circ} \mathrm{C}$, followed by freeze-drying to afford off-white powders.

Ligation Reaction. Solutions of protein containing the AzF residue in $50 \mathrm{mM}$ HEPES buffer, $\mathrm{pH} \mathrm{7.5,} \mathrm{were} \mathrm{added} \mathrm{to}$ solutions of the $\mathrm{C} 3$ or $\mathrm{C} 4$ tags, followed by addition of a premixed solution of $\mathrm{CuSO}_{4}$ and copper-binding ligand, and finally sodium ascorbate to yield a total reaction volume of 0.8 $\mathrm{mL}$. The final concentrations were $0.05 \mathrm{mM}$ protein, $0.5 \mathrm{mM}$ tag, $0.2 \mathrm{mM} \mathrm{CuSO}_{4}, 1 \mathrm{mM}$ copper-binding ligand, and $5 \mathrm{mM}$ sodium ascorbate. ${ }^{45}$ Copper-binding ligands tested were BTTAA (2-[4-\{(bis[(1-tert-butyl-1H-1,2,3-triazol-4-yl)methyl]amino)methyl $\}-1 H$-1,2,3-triazol-1-yl] acetic acid), THPTA (tris[(1-hydroxy-propyl-1H-1,2,3-triazol-4-yl)methyl]amine), and TBTA (tris[(1-benzyl-1H-1,2,3-triazol-4-yl)methyl] amine). BTTAA performed best with ubiquitin Glu18AzF (Figure S1) and was used in all subsequent reactions. The ligation reactions of the AzF mutants of p75 ICD and sortase A were conducted in the additional presence of $0.5 \mathrm{mM}$ glycerol and $5 \mathrm{mM}$ aminoguanidine to prevent protein aggregation caused by byproducts from ascorbate oxidation. ${ }^{46,47}$ All ligation reactions were performed in a glovebox under $\mathrm{N}_{2}$ atmosphere at room temperature with gentle stirring for $16 \mathrm{~h}$, and all solvents were degassed by vacuum suction prior to use. The ligation reaction was terminated by the addition of EDTA to a final concentration of $5 \mathrm{mM}$ and standing for $30 \mathrm{~min}$ in air. The buffer was exchanged for NMR buffer and concentrated by ultrafiltration using Amicon centrifugal filter devices (3000 MWCO for ubiquitin and p75 ICD, 10000 MWCO for sortase A).
NMR Spectroscopy. All NMR spectra were recorded at 25 ${ }^{\circ} \mathrm{C}$ on a $600 \mathrm{MHz}$ Bruker Avance NMR spectrometer equipped with a cryoprobe. A $3 \mathrm{D}$ NOESY $-{ }^{15} \mathrm{~N}$-HSQC spectrum was recorded of ubiquitin Glu18AzF tagged with $\mathrm{C}_{3}-\mathrm{Y}^{3+}$ and $\mathrm{C} 4-$ $\mathrm{Y}^{3+}$ to confirm the resonance assignments of the ${ }^{15} \mathrm{~N}-\mathrm{HSQC}$ spectra in the diamagnetic state. PCS values were measured in the ${ }^{1} \mathrm{H}$ dimension of ${ }^{15} \mathrm{~N}-\mathrm{HSQC}$ spectra.

$\Delta \chi$ Tensor Fits. The experimental PCS values measured for the ubiquitin mutants Glu18AzF and Thr66AzF were used to fit magnetic susceptibility anisotropy $(\Delta \chi)$ tensors to the first conformer of the NMR structure $1 \mathrm{D} 3 \mathrm{Z},{ }^{48}$ using the program PyParaTools (M. Stanton-Cook and T.H., publication in preparation). The covalent structures of the tags ligated to ubiquitin Glu18AzF and Thr66AzF were modeled on the protein coordinates using the crystal structures of the lanthanide chelates as described previously. ${ }^{24,28} 200000$ conformations were generated by randomly altering the dihedral angles of the tethers linking the AzF side chain with the lanthanide chelating moiety. For both tags, the variable dihedral angles included the $\chi_{1}$ angle of $\mathrm{AzF}\left(60^{\circ},-60^{\circ}\right.$, and $180^{\circ}$ ), the $\chi_{2}$ angle of $\mathrm{AzF}$ (any rotation angle), the dihedral angle of the conjugated bond between the phenyl and triazole groups $\left(0^{\circ}\right.$ and $\left.180^{\circ}\right)$, and the dihedral angle between the triazole and the following $\mathrm{CH}_{2}$ group (any rotation angle; see Figure 1 for the structures of the ligated tags). For the $\mathrm{C} 4 \mathrm{tag}$, the variable dihedral angles also comprised the angle between the $\mathrm{CH}_{2}$ group and the amide nitrogen (any rotation angle). An uncertainty range of $\pm 10^{\circ}$ was allowed for all dihedral bond variations. Conformations with steric clashes between protein and tag were eliminated. The $\Delta \chi$ tensors were fitted to each of the remaining conformers using the experimental PCSs. The final $\Delta \chi$ tensor was read from the conformer with the best least-squares fit to the experimental PCS data. ${ }^{24,28}$ Error estimates of the $\Delta \chi$ tensors and metal position were obtained by a Monte Carlo protocol that used a random selection of $90 \%$ of the experimental PCS data, and by comparison with the metal positions obtained by the program Numbat that does not restrain the metal positions. ${ }^{49}$

\section{RESULTS}

Tag Design. The alkyne-bearing tags C3 and C4 (Figure 1) were synthesized based on previous experience that lanthanide complexes derived from cyclen (1,4,7,10-tetraazacyclododecane) are very stable and deliver sizable PCSs. ${ }^{2,24,50-52}$ The chirality of the phenylethylamide pendants in the C3 and C4 tags is the same as the chirality in the related $\mathrm{C} 1 \mathrm{tag}^{24}$ that was designed for attachment to cysteine residues (the $\mathrm{C} 2$ tag is the same molecule as the $\mathrm{C} 1$ tag except for opposite chirality of the phenylethylamide pendants). The tags were synthesized in enantiomerically pure form to ensure that only a single stereoisomer is obtained following the ligation reaction with the target protein. ${ }^{16,53}$

Ligation Reactions. The click reactions (Figure 1) were performed at room temperature at $\mathrm{pH} 7.5$ in $50 \mathrm{mM}$ HEPES buffer, catalyzed by $0.2 \mathrm{mM} \mathrm{Cu}(\mathrm{I})$ ions in the presence of 5 $\mathrm{mM}$ sodium ascorbate and $1 \mathrm{mM}$ of the $\mathrm{Cu}(\mathrm{I})$-stabilizing ligand BTTAA $^{45}$ Using the Glu18AzF mutant of ubiquitin as a model system with $\mathrm{C} 3-\mathrm{Tm}^{3+}$ and $\mathrm{C} 4-\mathrm{Tm}^{3+}$, Cu-BTTAA performed significantly better as a catalyst than $\mathrm{Cu}-\mathrm{THPTA}^{47}$ or $\mathrm{Cu}$ $\mathrm{TBTA}^{54}$ (Figure S1). Addition of aminoguanidine and glycerol $^{47}$ was found to be effective against protein degradation by byproducts of ascorbate oxidation ${ }^{46}$ and greatly improved the yields for proteins other than ubiquitin (Figures S2 and S3). 
Quantitative reaction yields were obtained only for the C4 tag, decreasing by up to half for the C3 tag. Attempts to improve the yields by addition of more Cu-BTTAA catalyst $5 \mathrm{~h}$ after the start of the ligation reaction did not increase the ligation yields in two proteins tested (sortase A Ser99AzF and ubiquitin Thr66AzF, both with C-terminal $\mathrm{His}_{6}$ tag). We attribute the reduced yields of the $\mathrm{C} 3$ versus the $\mathrm{C} 4$ tag to the steric demand of the BTTAA catalyst, which is harder to accommodate for short tethers between protein and cyclen moiety.

Observation of PCSs with the C3 and C4 Tags. Sizeable PCSs were observed when the C3 and C4 tags loaded with $\mathrm{Tm}^{3+}$ and $\mathrm{Tb}^{3+}$ ions were attached to the ubiquitin mutant Glu18AzF (Figure 3, Table S1). As in the case of the $\mathrm{C} 1$ and $\mathrm{C} 2$ tags, ${ }^{24}$ the chiral purity of the $\mathrm{C} 3$ and $\mathrm{C} 4$ tags prevented the formation of diastereomers, which is a prerequisite for straightforward PCS measurements. ${ }^{16,53}$ Regardless of the lengths of the tethers linking the metal ion to the backbone of the protein, both tags clearly hold the lanthanide ions in a

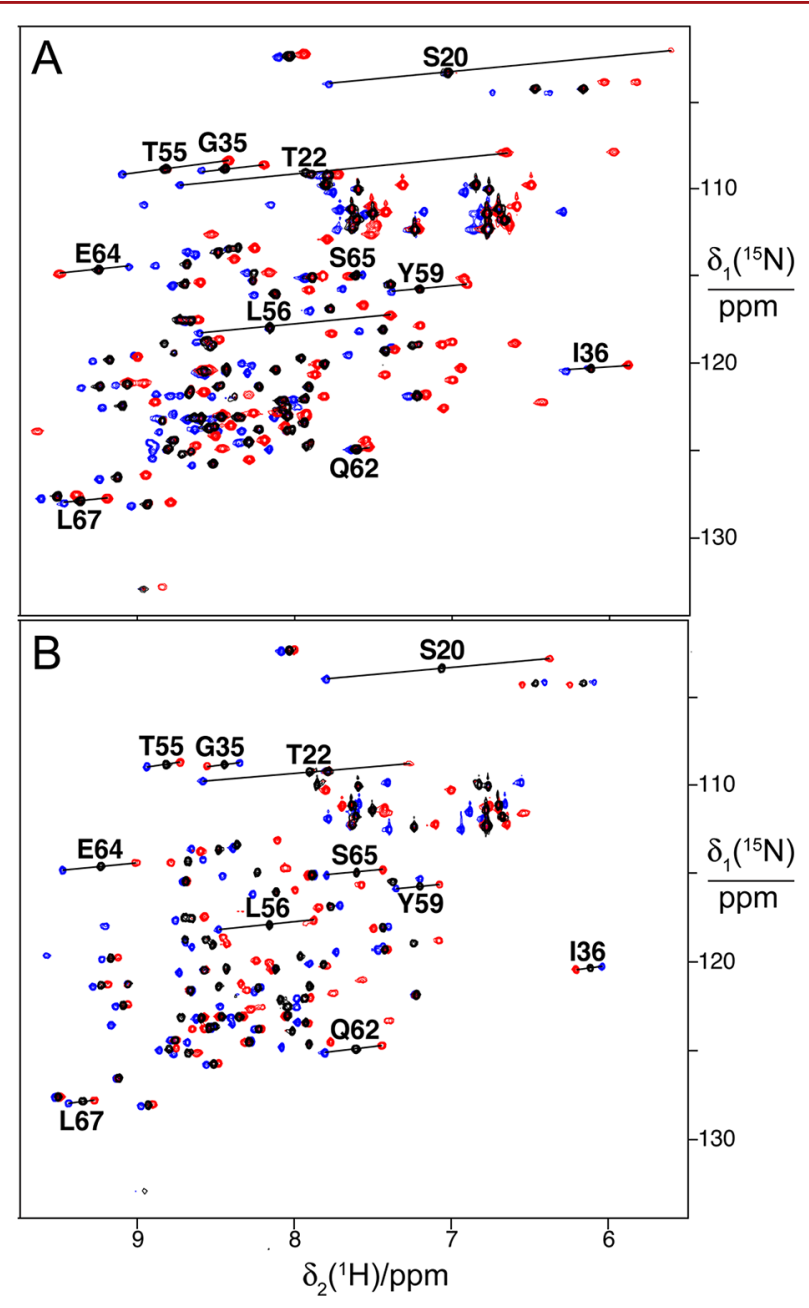

Figure 3. Superimposition of ${ }^{15} \mathrm{~N}-\mathrm{HSQC}$ spectra of $0.1 \mathrm{mM}$ solutions of uniformly ${ }^{15} \mathrm{~N}$-labeled ubiquitin with $\mathrm{C} 3$ and $\mathrm{C} 4$ tags ligated to an AzF residue in position 18. Spectra with tags loaded with $\mathrm{Y}^{3+}$ are shown in black, $\mathrm{Tb}^{3+}$ in red, and $\mathrm{Tm}^{3+}$ in blue. All spectra were recorded in $50 \mathrm{mM}$ HEPES, $\mathrm{pH} 7.0$, at $25{ }^{\circ} \mathrm{C}$ on a $600 \mathrm{MHz}$ NMR spectrometer. Selected diamagnetic cross-peaks are labeled with their resonance assignments and connected by lines with their paramagnetic partners. (A) Ubiquitin Glu18AzF with C3 tag. (B) Same as (A) but with the $\mathrm{C} 4 \mathrm{tag}$. sufficiently well-defined orientation with respect to the protein that the PCSs do not average to zero.

$\Delta \chi$ Tensors Generated by the C3 and C4 Tags. Table 1 reports the $\Delta \chi$ tensors determined with the $\mathrm{C} 3$ and $\mathrm{C} 4$ tags loaded with $\mathrm{Tm}^{3+}$ and $\mathrm{Tb}^{3+}$. The $\Delta \chi$ tensors are up to four times smaller than those observed previously for the related cyclen tag $\mathrm{C} 1$ that we designed for attachment via a disulfide bond. ${ }^{24}$ Considering that the lanthanide coordination is identical in the $\mathrm{C} 1, \mathrm{C} 3$, and $\mathrm{C} 4$ tags, the decreased $\Delta \chi$ tensors of the $\mathrm{C} 3$ and $\mathrm{C} 4$ tags indicate residual mobility of the tags relative to the protein. While both tags produced $\Delta \chi$ tensors of similar magnitude, the $\Delta \chi$ tensor fits for the $\mathrm{C} 3$ tag produced better quality factors (Table 1) and correspondingly closer correlations between experimental and back-calculated PCSs (Figure S4). Imperfect correlations between experimental and back-calculated PCSs are expected whenever the metal position varies, as PCSs depend on the distance between the paramagnetic center and the nuclear spin, and fits by a single $\Delta \chi$ tensor implicitly assume a single metal position. Importantly, however, the PCS correlations obtained by the fitting of a single $\Delta \chi$ tensor are sufficiently good for using the tensor to predict the PCSs of other nuclear spins in the protein, within the uncertainty range indicated by the correlation plots.

The fits obtained for ubiquitin Glu18AzF with the C3 and $\mathrm{C} 4$ tags positioned the respective paramagnetic centers more than $6 \AA$ apart from each other (Figure 4) and produced very different effective $\Delta \chi$ tensor orientations. The complementarity of the PCSs generated by the two tags greatly enhances the structural information that can be derived for the same AzF mutant. To minimize potential problems associated with long tethers and to evaluate the general feasibility of ligation, we focused our further studies on the more challenging C3 tag.

PCSs with Other Proteins. It is important to assess the reliability with which the new tags can generate PCSs at different sites in different proteins. Figure 4 shows that the tags were highly solvent exposed in the ubiquitin Glu18AzF mutant, suggesting that the generation of large PCSs does not depend on immobilization by contacts with the protein, as may be the case for the $\mathrm{C} 1$ and $\mathrm{C} 2$ tags. Indeed, when we tested the $\mathrm{C} 3 \mathrm{tag}$ with the ubiquitin mutant Thr66AzF, sizable PCSs were observed with $\mathrm{Tm}^{3+}$ and $\mathrm{Tb}^{3+}$ (Figure S5 and Table S1). The $\Delta \chi$ tensors (Table S2) were about 2 -fold larger than for the mutant Glu18AzF (Table 1), which may be attributed to some interactions between the tag and the protein (Figure S7).

To test the ligation yields for proteins containing cysteine residues, we further tested the $\mathrm{C} 3$ tag with the Staphylococcus aureus sortase $\mathrm{A}^{55}$ mutants Gln55AzF and Ser99AzF, and with the Lys350AzF mutant of the intracellular domain of the p75 neutrophin receptor (p75 ICD), ${ }^{56}$ all with C-terminal $\mathrm{His}_{6}$ tag. PCSs were observed in all samples (Figures S3, S5, S8, and S10). Furthermore, ligation yields of about $60 \%$ were achieved routinely (Figures S2, S3, S10, and S11), demonstrating that cysteine residues (present in sortase A and p75 ICD) do not interfere with the reaction. Spectral overlap prohibited the determination of $\Delta \chi$ tensors for $\mathrm{p} 75$ ICD samples, and no $\Delta \chi$ tensor fit was attempted for the sortase A Ser99AzF mutant because the protein was prone to precipitation. A $\Delta \chi$ tensor was, however, fitted to $S$. aureus sortase A Gln55AzF with the C3- $\mathrm{Tm}^{3+}$ tag. The fit revealed a $\Delta \chi$ tensor as large as that observed for the Thr66AzF mutant of ubiquitin (Tables S2 and S4).

His $_{6}$ Tags Inhibit $\mathrm{Cu}(\mathrm{I})$-Catalyzed Click Reactions. As the imidazole side chain of histidine residues may coordinate 
Table 1. $\Delta \chi$ Tensor Parameters of Ubiquitin Glu18AzF with C3 and C4 Tags Determined by a Rotamer Library Approach ${ }^{a, b}$

\begin{tabular}{|c|c|c|c|c|c|c|c|c|c|}
\hline & $\Delta \chi_{\mathrm{ax}}$ & $\Delta \chi_{\mathrm{rh}}$ & $Q$ & $x$ & $y$ & $z$ & $\alpha$ & $\beta$ & $\gamma$ \\
\hline $\mathrm{C} 3-\mathrm{Tb}$ & $9.0(0.2)$ & $2.3(0.2)$ & 0.11 & 58.051 & -97.841 & 3.445 & $169(1)$ & 49 (1) & $22(2)$ \\
\hline $\mathrm{C} 3-\mathrm{Tm}$ & $-5.4(0.1)$ & $-1.7(0.1)$ & 0.10 & 58.051 & -97.841 & 3.445 & 165 (1) & $46(1)$ & $27(1)$ \\
\hline $\mathrm{C} 4-\mathrm{Tb}$ & $9.7(0.3)$ & $3.4(0.2)$ & 0.35 & 61.821 & -97.321 & 8.980 & $37(1)$ & $46(1)$ & $71(1)$ \\
\hline $\mathrm{C} 4-\mathrm{Tm}$ & $-9.7(0.3)$ & $-3.0(0.2)$ & 0.33 & 61.821 & -97.321 & 8.980 & $36(1)$ & $50(1)$ & $70(1)$ \\
\hline
\end{tabular}

${ }^{a_{T}}$ The axial and rhombic components of the $\Delta \chi$ tensors are given in $10^{-32} \mathrm{~m}^{3}$ and the Euler angles in degrees, using the $z y z$ convention and unique tensor representation. ${ }^{49}$ The metal coordinates and tensor parameters are reported relative to the first conformer of the NMR structure of ubiquitin (PDB ID 1D3Z). ${ }^{48}$ Fits were performed using a rotamer library to identify all possible tag conformations and metal positions. In a second step, $\Delta \chi$ tensors were fitted to every metal position, simultaneously using the PCS data of $\mathrm{Tm}^{3+}$ and $\mathrm{Tb}^{3+}$. The table displays the overall best fits. Standard deviations (in brackets) were determined from fits obtained by using the same metal position while randomly omitting $10 \%$ of the PCS data. Quality factors were calculated as the root-mean-square deviation between experimental and back-calculated PCSs divided by the root-mean-square of the experimental PCSs. ${ }^{b} \Delta \chi$ tensor fits were also performed using Numbat ${ }^{49}$ without any restraints on the covalent structures of the tags. The resulting quality factors for ubiquitin Glu18AzF were 0.11 for $\mathrm{C} 3-\mathrm{Tb}, 0.10$ for $\mathrm{C} 3-\mathrm{Tm}, 0.35$ for $\mathrm{C} 4-\mathrm{Tb}$, and 0.33 for $\mathrm{C} 4-\mathrm{Tm}$, and the metal shifted by 0.3 and $1.3 \AA$ for the $\mathrm{C} 3$ and $\mathrm{C} 4 \mathrm{tag}$, respectively.

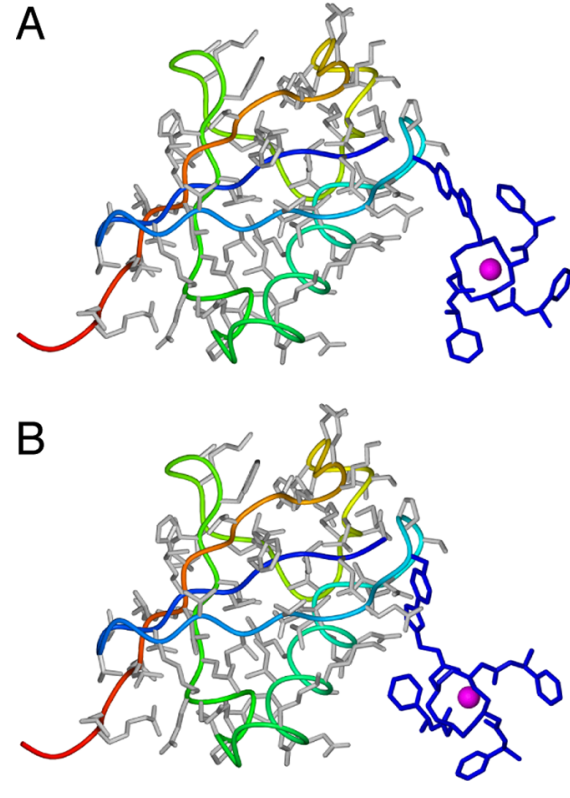

Figure 4. Models of ubiquitin Glu18AzF with (A) C3 and (B) C4 tags. The first conformer of the NMR structure $1 \mathrm{D} 3 \mathrm{Z}^{48}$ is displayed as a ribbon drawing with the heavy atoms of the amino acid side chains in gray. The tags are shown in blue with the lanthanide as a magenta sphere. The positions and orientations of the $\mathrm{C} 3$ and $\mathrm{C} 4$ tags pertain to the best fits of the $\Delta \chi$ tensors to the experimental PCSs. Note that a range of tag conformations exists due to rotatable bonds in the linker between metal and protein, leading to effective $\Delta \chi$ tensors of different size and shape (Table 1).

copper ions, we tested whether $\mathrm{His}_{6}$ tags could inhibit the ligation. Indeed, a $\mathrm{C}$-terminal $\mathrm{His}_{6}$ tag in the ubiquitin Glu18AzF mutant reduced the ligation yield with the $\mathrm{C} 3$ and $\mathrm{C} 4$ tag to about $40 \%$ (Figure S11). Similarly, using a construct of sortase A Gln55AzF without $\mathrm{His}_{6}$ tag produced a ligation yield of over $80 \%$ with the C3 tag (data not shown), indicating that near-quantitative ligation yields are significantly easier to achieve in the absence of $\mathrm{His}_{6}$ tags.

\section{DISCUSSION}

The present work demonstrates that it is possible to generate large PCSs with lanthanide tags that do not depend on single cysteine residues for site-specific attachment. Eliminating the need to mutate cysteine residues presents a major advantage for large proteins that usually contain several cysteine residues. As a genetically encoded amino acid, AzF can be incorporated into the amino acid sequence at any selected site without restrictions. The $\mathrm{Cu}(\mathrm{I})$-catalyzed alkyne-azide cycloaddition is a bioorthogonal reaction that is selective for azido groups and thus compatible with any of the functional groups encountered in polypeptide chains made of natural amino acids.

Rigidity of the Tether Between Lanthanide and Protein. The 1,2,3-triazole moiety obtained by ligation of an alkyne with $\mathrm{AzF}$ is conjugated with the aromatic ring of $\mathrm{AzF}$, discouraging any dihedral angles other than $0^{\circ}$ and $180^{\circ}$ for the bond between the two rings. Furthermore, the plane of the phenyl ring of tyrosine and phenylalanine is usually oriented perpendicular to the $\mathrm{C}^{\alpha}-\mathrm{C}^{\beta}$ bond, ${ }^{57}$ constraining the $\chi_{2}$ angle of the AzF side chain. Finally, steric interactions with other protein side chains easily lock the $\chi_{1}$ angles of aromatic residues into a single rotamer. Overall, this makes the tether connecting the lanthanide chelate and the protein backbone remarkably rigid in view of the length of the tether, minimizing the averaging effects usually associated with long tethers.

In both tags investigated in this work, not all bonds are fixed and changes in dihedral angles for rotatable bonds in the tether lead to effective $\Delta \chi$ tensors that are smaller than expected for completely rigid attachment of the tags. Even in the presence of mobility, however, the fit of back-calculated versus experimental PCSs can produce reasonably good correlations between backcalculated and experimental PCSs (Figure S4, S6, S9), suggesting that the effective $\Delta \chi$ tensor determined from the protein PCSs can be used to obtain structural restraints for nuclear spins for which PCSs were measured but not used in the tensor fit. The uncertainty of PCSs predicted from the $\Delta \chi$ tensor can readily be estimated from the error range in the correlation plots of back-calculated versus experimental PCSs.

Ligation Yields. The present work investigated the performance of different $\mathrm{Cu}(\mathrm{I})$-stabilizing reagents to improve the yields with which the tags could be ligated to the AzF residue. BTTAA $^{45}$ proved to perform much better than THPTA $^{47}$ or TBTA. ${ }^{54}$ NMR spectroscopy offers particularly facile quantification of ligation yields, as cross-peaks from the ligated and unligated protein can both be resolved simultaneously. Obtaining complete ligation yields with the $\mathrm{C} 3$ tag was harder than with the $\mathrm{C} 4 \mathrm{tag}$, which can be explained by the greater steric demands associated with the shorter tether. To the best of our knowledge, the present work is the first describing near-quantitative yields for the $\mathrm{Cu}(\mathrm{I})$-catalyzed azide-alkyne cycloaddition reaction with a protein containing the AzF amino acid.

In principle, the azide group of $\mathrm{AzF}$ is sensitive to reduction during protein expression in E. coli and protein purification, 
leading to the recommendation to incorporate UAAs with alkyne rather than azide groups into the target proteins. ${ }^{41}$ In principle, a tether as short as those in the ligated products of Figure 1 can be obtained by reacting $p$-ethynyl-L-phenylalanine with an azide tag. However, all our attempts to attach a tag with a phenyl azide moiety to a ubiquitin mutant in which Glu18 was replaced by $p$-ethynyl-L-phenylalanine resulted in very low ligation yields (data not shown). Importantly, degradation of AzF during protein synthesis and purification proved to be no problem in the present work, as we could obtain quantitative ligation yields with $\mathrm{AzF}$ despite preparing all protein samples in vivo in E. coli.

As noted previously, ${ }^{47}$ the presence of $\mathrm{a} \mathrm{His}_{6}$ tag can lead to reduced ligation yields, presumably by a competition between the histidine side chains and the BTTAA ligand for binding copper. We obtained virtually quantitative ligation for a sortase A construct with the $\mathrm{C} 3$ tag after the $\mathrm{His}_{6}$ tag had been cleaved off.

For unknown reasons, it also proved important that the reducing agent ascorbate was added to the protein after the addition of the $\mathrm{Cu}$ (II) solution with BTTAA; addition of a preincubated mixture of ascorbate, $\mathrm{Cu}^{2+}$ ions, and BTTAA to the protein resulted in consistently lower ligation yields.

Incomplete ligation yields interfere remarkably little with the determination of accurate $\Delta \chi$ tensors. First, the fitting of $\Delta \chi$ tensor parameters depends foremost on larger PCSs, which are invariably derived from cross-peaks in the paramagnetic state that are well-separated from the corresponding cross-peaks in the diamagnetic state. Second, the chemical shifts of the diamagnetic reference (i.e., the protein ligated with a diamagnetic metal tag) usually change only in the vicinity of the tag, where paramagnetic relaxation enhancements (PRE) anyway broaden the NMR signals beyond detection in the paramagnetic protein. Finally, the uncertainty in the PCS can also be considerable for a strongly shifted peak if it is broadened by PRE. Error estimates of the PCS of each individual spin always have to be part of the input for $\Delta \chi$ tensor fits.

Concluding Remarks. An important result of the present work is that, although the tether to the protein resulting from a click reaction with $\mathrm{AzF}$ is considerably longer than the disulfide bond tethers of the related $\mathrm{C} 1$ and $\mathrm{C} 2$ tags, ${ }^{24,40}$ the $\mathrm{C} 3$ and $\mathrm{C} 4$ tags generate sizable PCSs with remarkable reliability. Obviously, lanthanide tags that are attached to the protein at only a single site are much more versatile than tags with twoarmed attachments that are known to afford better immobilization of the lanthanide $27,28,30,50-52,58$ but require prior structural information or cumbersome optimization of the tethers, 6 limiting their general applicability.

While recent advances allow the site-specific incorporation of many different unnatural amino acids into proteins, ${ }^{59}$ only one of them (2-amino-3-(8-hydroxyquinolin-3-yl)-propanoic acid) ${ }^{60}$ could potentially bind lanthanides. Unfortunately, incorporation of this UAA triggers metal-mediated protein oligomerization, ${ }^{61}$ which is also a potential problem associated with bipyridyl-alanine ${ }^{62}$ after binding paramagnetic $\mathrm{Co}(\mathrm{II}) .{ }^{63}$ In our hands, the $\mathrm{Cu}(\mathrm{I})$-catalyzed click reactions were usually accompanied by protein precipitation during the ligation reaction, but only the p75 ICD samples continued to precipitate during NMR measurements. The improved sample stability compared to the metal binding UAAs can be attributed to the fact that the $\mathrm{C} 3$ and $\mathrm{C} 4$ tags occupy all but one of the coordination sites of the lanthanide ion, leaving no opportunity for metal-mediated cross-links between different protein molecules.

In conclusion, the additional reaction step associated with click chemistry is well worth the effort. The new tags extend the use of PCSs to a vastly greater range of proteins and tagging sites than any previous lanthanide tag.

\section{ASSOCIATED CONTENT}

\section{S Supporting Information}

Ligation yields obtained using different copper-complexing ligands, effect of aminoguanidine and glycerol on the click ligation yields, pseudocontact shifts of backbone amide protons of ubiquitin Glu18AzF with $\mathrm{C} 3$ and $\mathrm{C} 4$ tags, correlation between back-calculated and experimental pseudocontact shifts of ubiquitin Glu18AzF with $\mathrm{C} 3$ and $\mathrm{C} 4$ tags, ${ }^{15} \mathrm{~N}-\mathrm{HSQC}$ spectra of ubiquitin Thr66AzF with $\mathrm{C} 3 \mathrm{tag}\left(\mathrm{Tm}^{3+}, \mathrm{Tb}^{3+}\right), \Delta \chi$ tensor parameters of ubiquitin Thr66AzF with C3 tag, correlation between back-calculated and experimental pseudocontact shifts of ubiquitin Thr66AzF ligated with C3 tag, model of ubiquitin Thr66AzF with C3 tag, ${ }^{15} \mathrm{~N}-\mathrm{HSQC}$ spectra of $S$. aureus sortase A Gln55AzF with $\mathrm{C} 3 \mathrm{tag}$, pseudocontact shifts of backbone amide protons of $S$. aureus sortase A Gln55AzF with C3 tag, $\Delta \chi$ tensor parameters of $S$. aureus sortase A Gln55AzF with $\mathrm{C} 3 \mathrm{tag}$, correlation between back-calculated and experimental pseudocontact shifts of $S$. aureus sortase A Gln55AzF with C3-Tm tag, ${ }^{15} \mathrm{~N}-\mathrm{HSQC}$ spectra of p75 ICD Lys350AzF with C3 tag, ligation yields obtained with and without $\mathrm{His}_{6}$ tag, with $\mathrm{C} 3$ or $\mathrm{C} 4$ tags. This material is available free of charge via the Internet at http://pubs.acs.org.

\section{AUTHOR INFORMATION}

\section{Corresponding Author}

*Gottfried Otting: Fax +61-2-61250750; E-mail: gottfried. otting@anu.edu.au. Bim Graham: Fax +61-3-99039543; E-mail: bim.graham@monash.edu.

\section{Notes}

The authors declare no competing financial interest.

\section{ACKNOWLEDGMENTS}

We thank Prof. Peter G. Schultz for the pEVOL plasmid for $p$ azido-L-phenylalanyl-tRNA synthetase, and Drs. Anatoly Sharipo and Marçal Vilar for the expression vectors of Staphylococcus aureus sortase A and the rat p75 neurotrophin receptor, respectively. This work was supported by the Australian Research Council, including an Australian Research Fellowship to K. O. and a Future Fellowship to T. H.

\section{REFERENCES}

(1) Otting, G. (2008) Prospects for lanthanides in structural biology by NMR. J. Biomol. NMR 42, 1-9.

(2) Allegrozzi, M., Bertini, I., Janik, M. B. L., Lee, Y. M., Liu, G., and Luchinat, C. (2000) Lanthanide-induced pseudocontact shifts for solution structure refinements of macromolecules in shells up to $40 \AA$ from the metal ion. J. Am. Chem. Soc. 122, 4154-4161.

(3) Schmitz, C., Vernon, R., Otting, G., Baker, D., and Huber, T. (2012) Protein structure determination from pseudocontact shifts using ROSETTA. J. Mol. Biol. 416, 668-677.

(4) Pintacuda, G., Park, A. Y., Keniry, M. A., Dixon, N. E., and Otting, G. (2006) Lanthanide labeling offers fast NMR approach to 3D structure determinations of protein-protein complexes. J. Am. Chem. Soc. 128, 3696-3702.

(5) Keizers, P. H. J., Mersinli, B., Reinle, W., Donauer, J., Hiruma, Y., Hannemann, F., Overhand, M., Bernhart, R., and Ubbink, M. (2010) A solution model of the complex formed by adrenodoxin and 
adrenodoxin reductase determined by paramagnetic NMR spectroscopy. Biochemistry 49, 6846-6855.

(6) Saio, T., Yokochi, M., Kumeta, H., and Inagaki, F. (2010) PCSbased structure determination of protein-protein complexes. J. Biomol. NMR 46, 271-280.

(7) John, M., Pintacuda, G., Park, A. Y., Dixon, N. E., and Otting, G. (2006) Structure determination of protein-ligand complexes by transferred paramagnetic shifts. J. Am. Chem. Soc. 128, 12910-12916.

(8) Zhuang, T., Lee, H. S., Imperiali, B., and Prestegard, J. H. (2008) Structure determination of a Galectin-3 - carbohydrate complex using paramagnetism-based NMR constraints. Protein Sci. 17, 1220-1231.

(9) Saio, T., Ogura, K., Shimizu, K., Yokochi, M., Burke, T. R., and Inagaki, F. (2011) An NMR strategy for fragment-based ligand screening utilizing a paramagnetic lanthanide probe. J. Biomol. NMR 51, 395-408.

(10) Rodriguez-Castañeda, F., Haberz, P., Leonov, A., and Griesinger, C. (2006) Paramagnetic tagging of diamagnetic proteins for solution NMR. Magn. Reson. Chem. 44, 10-16.

(11) Su, X.-C., and Otting, G. (2010) Paramagnetic labelling of proteins and oligonucleotides for NMR. J. Biomol. NMR 46, 101-112.

(12) Su, X.-C., and Otting, G. (2011) Erratum to: Paramagnetic labelling of proteins and oligonucleotides for NMR. J. Biomol. NMR 50, 99-100.

(13) Keizers, P. H. J., and Ubbink, M. (2011) Paramagnetic tagging for protein structure and dynamics analysis. Prog. NMR Spectrosc. 58, $88-96$.

(14) Koehler, J., and Meiler, J. (2011) Expanding the utility of NMR restraints with paramagnetic compounds: background and practical aspects. Prog. NMR Spectrosc. 59, 360-389.

(15) Dvoretsky, A., Gaponenko, V., and Rosevear, P. R. (2002) Derivation of structural restraints using a thiol-reactive chelator. FEBS Lett. 528, 189-192.

(16) Ikegami, T., Verdier, L., Sakhaii, P., Grimme, S., Pescatore, B., Saxena, K., Fiebig, K. M., and Griesinger, C. (2004) Novel techniques for weak alignment of proteins in solution using chemical tags coordinating lanthanide ions. J. Biomol. NMR 29, 339-349.

(17) Leonov, A., Voigt, B., Rodriguez-Castañeda, F., Sakhaii, P., and Griesinger, C. (2005) Convenient synthesis of multifunctional EDTAbased chiral metal chelates substituted with an S-mesylcysteine. Chem.-Eur. J. 11, 3342-3348.

(18) Haberz, P., Rodriguez-Castañeda, F., Junker, J., Becker, S., Leonov, A., and Griesinger, C. (2006) Two new chiral EDTA-based metal chelates for weak alignment of proteins in solution. Org. Lett. 8, $1275-1278$.

(19) Su, X.-C., Huber, T., Dixon, N. E., and Otting, G. (2006) Sitespecific labelling of proteins with a rigid lanthanide-binding tag. ChemBioChem 7, 1599-1604.

(20) Su, X.-C., Man, B., Beeren, S., Liang, H., Simonsen, S., Schmitz, C., Huber, T., Messerle, B. A., and Otting, G. (2008) A dipicolinic acid tag for rigid lanthanide tagging of proteins and paramagnetic NMR spectroscopy. J. Am. Chem. Soc. 130, 10486-10487.

(21) Su, X.-C., McAndrew, K., Huber, T., and Otting, G. (2008) Lanthanide-binding peptides for NMR measurements of residual dipolar couplings and paramagnetic effects from multiple angles. J. Am. Chem. Soc. 130, 1681-1687.

(22) Häussinger, D., Huang, J., and Grzesiek, S. (2009) DOTA-M8: An extremely rigid, high-affinity lanthanide chelating tag for PCS NMR spectroscopy. J. Am. Chem. Soc. 131, 14761-14767.

(23) Man, B., Su, X.-C., Liang, H., Simonsen, S., Huber, T., Messerle, B. A., and Otting, G. (2010) 3-Mercapto-2,6-pyridinedicarboxylic acid: a small lanthanide-binding tag for protein studies by NMR spectroscopy. Chem.-Eur. J. 16, 3827-3832.

(24) Graham, B., Loh, C. T., Swarbrick, J. D., Ung, P., Shin, J., Yagi, H., Jia, X., Chhabra, S., Pintacuda, G., Huber, T., and Otting, G. (2011) DOTA-amide lanthanide tag for reliable generation of pseudocontact shifts in protein NMR spectra. Bioconjugate Chem. 22, 2118-2125.
(25) Jia, X., Maleckis, A., Huber, T., and Otting, G. (2011) 4,4'dithiobisdipicolinic acid: a small and convenient lanthanide binding tag for protein NMR spectroscopy. Chem.-Eur. J. 17, 6830-6836.

(26) Peters, F., Maestre-Martinez, M., Leonov, A., Kovačič, L., Becker, S., Boelens, R., and Griesinger, C. (2011) Cys-Ph-TAHA: a lanthanide binding tag for RDC and PCS enhanced protein NMR. $J$. Biomol. NMR 51, 329-337.

(27) Swarbrick, J. D., Ung, P., Chhabra, S., and Graham, B. (2011) An iminodiacetic acid based lanthanide binding tag for paramagnetic exchange NMR spectroscopy. Angew. Chem., Int. Ed. 50, 4403-4406. (28) Swarbrick, J. D., Ung, P., Su, X.-C., Maleckis, A., Chhabra, S., Huber, T., Otting, G., and Graham, B. (2011) Engineering of a bischelator motif into a protein $\alpha$-helix for rigid lanthanide binding and paramagnetic NMR spectroscopy. Chem. Commun. 47, 7368-7370.

(29) Li, Q. F., Yang, Y., Maleckis, A., Otting, G., and Su, X.-C. (2012) Thiol-ene reaction: a versatile tool in site-specific labelling of proteins with chemically inert tags for paramagnetic NMR. Chem. Commun. 48, 2704-2706.

(30) Liu, W. M., Keizers, P. H., Hass, M. A., Blok, A., Timmer, M., Sarris, A. J., Overhand, M., and Ubbink, M. (2012) A pH-sensitive, colourful, lanthanide-chelating paramagnetic NMR probe. J. Am. Chem. Soc. 134, 17306-17313.

(31) Yang, Y., Li, Q. F., Cao, C., Huang, F., and Su, X.-C. (2012) Site-specific labeling of proteins with a chemically stable, high-affinity tag for protein study. Chem.-Eur. J.,.

(32) Ma, C., and Opella, S. J. (2000) Lanthanide ions bind specifically to an added "EF-hand" and orient a membrane protein in micelles for solution NMR spectroscopy. J. Magn. Reson. 146, 381384.

(33) Wöhnert, J., Franz, K. J., Nitz, M., Imperiali, B., and Schwalbe, H. (2003) Protein alignment by a coexpressed lanthanide-binding tag for the measurement of residual dipolar couplings. J. Am. Chem. Soc. 125, 13338-13339.

(34) Martin, L. J., Hähnke, M. J., Nitz, M., Wöhnert, J., Silvaggi, N. R., Allen, K. N., Schwalbe, H., and Imperiali, B. (2007) Doublelanthanide-binding tags: design, photophysical properties, and NMR applications. J. Am. Chem. Soc. 129, 7106-7113.

(35) Saio, T., Ogura, K., Yokochi, M., Kobashigawa, Y., and Inagaki, F. (2009) Two-point anchoring of a lanthanide-binding peptide to a target protein enhances the paramagnetic anisotropic effect. J. Biomol. NMR 44, 157-166.

(36) Barthelmes, K., Reynolds, A. M., Peisach, E., Jonker, H. R. A., DeNunzio, N. J., Allen, K. N., Imperiali, B., and Schwalbe, H. (2011) Engineering encodable lanthanide-binding tags into loop regions of proteins. J. Am. Chem. Soc. 133, 808-819.

(37) Su, X.-C., Liang, H., Loscha, K. V., and Otting, G. (2009) $\left[\operatorname{Ln}(\mathrm{DPA})_{3}\right]^{3-}$ is a convenient paramagnetic shift reagent for protein NMR studies. J. Am. Chem. Soc. 131, 10352-10353.

(38) Jia, X., Yagi, H., Su, X.-C., Stanton-Cook, M., Huber, T., and Otting, G. (2011) Engineering $\left[\operatorname{Ln}(\mathrm{DPA})_{3}\right]^{3-}$ binding sites in proteins: a widely applicable method for tagging proteins with lanthanide ions. $J$. Biomol. NMR 50, 411-420.

(39) Chin, J. W., Santoro, S. W., Martin, A. B., King, D. S., Wang, L., and Schultz, P. G. (2002) Addition of $p$-azido- $L$-phenylalanine to the genetic code of Escherichia coli. J. Am. Chem. Soc. 124, 9026-9027.

(40) de la Cruz, L., Nguyen, T. H. D., Ozawa, K., Shin, J., Graham, B., Huber, T., and Otting, G. (2011) Binding of low molecular weight inhibitors promotes large conformational changes in the dengue virus NS2B-NS3 protease: fold analysis by pseudocontact shifts. J. Am. Chem. Soc. 133, 19205-19215.

(41) Milles, S., Tyagi, S., Banterle, N., Koehler, C., VanDelinder, V., Plass, T., Neal, A. P., and Lemke, E. A. (2012) Click strategies for single-molecule protein fluorescence. J. Am. Chem. Soc. 134, 51875195.

(42) Young, T. S., Ahmad, I., Yin, J. A., and Schultz, P. G. (2010) An enhanced system for unnatural amino acid mutagenesis in Escherichia coli. J. Mol. Biol. 395, 361-374.

(43) Neylon, C., Brown, S. E., Kralicek, A. V., Miles, C. S., Love, C. A., and Dixon, N. E. (2000) Interaction of the Escherichia coli 
replication terminator protein (Tus) with DNA: a model derived from DNA-binding studies of mutant proteins by surface plasmon resonance. Biochemistry 39, 11989-11999.

(44) Sivashanmugam, A., Murray, V., Cui, C., Zhang, Y., Wang, J., and Li, Q. (2009) Practical protocols for production of very high yields of recombinant proteins using Escherichia coli. Protein Sci. 18, 936948.

(45) Besanceney-Webler, C., Jiang, H., Zheng, T., Feng, L., Soriano Del Amo, D., Wang, W., Klivansky, L. M., Marlow, F. L., and Wu, P. (2011) Increasing the efficacy of bioorthogonal click reactions for bioconjugation: A comparative study. Angew. Chem., Int. Ed. 50, 80518056.

(46) Hlavaty, J. J., and Nowak, T. (1997) Affinity cleavage at the metal-binding site of phosphoenolpyruvate. Biochemistry 36, 1551415524.

(47) Hong, V., Presolski, S. I., Ma, C., and Finn, M. G. (2009) Analysis and optimization of copper-catalyzed azide-alkyne cycloaddition for bioconjugation. Angew. Chem., Int. Ed. 48, 9879-9883.

(48) Cornilescu, G., Marquardt, L. J., Ottiger, M., and Bax, A. (1998) Validation of protein structure from anisotropic carbonyl chemical shifts in a dilute liquid crystalline phase. J. Am. Chem. Soc. 120, 68366837.

(49) Schmitz, C., Stanton-Cook, M. J., Su, X.-C., Otting, G., and Huber, T. (2008) Numbat: an interactive software tool for fitting $\Delta \chi$ tensors to molecular coordinates using pseudocontact shifts. J. Biomol. NMR 41, 179-189.

(50) Keizers, P. H. J., Desreux, J. F., Overhand, M., and Ubbink, M. (2007) Increased paramagnetic effect of a lanthanide protein probe by two-point attachment. J. Am. Chem. Soc. 129, 9292-9293.

(51) Keizers, P. H. J., Saragliadis, A., Hiruma, Y., Overhand, M., and Ubbink, M. (2008) Design, synthesis, and evaluation of a lanthanide chelating protein probe: CLaNP-5 yields predictable paramagnetic effects independent of environment. J. Am. Chem. Soc. 130, 1480214812.

(52) Vlasie, M. D., Comuzzi, C., van den Nieuwendijk, A. M. C. H., Prudêncio, M., Overhand, M., and Ubbink, M. (2007) Long-rangedistance NMR effects in a protein labeled with a lanthanide-DOTA chelate. Chem.-Eur. J. 13, 1715-1723.

(53) Pintacuda, G., Moshref, A., Leonchiks, A., Sharipo, A., and Otting, G. (2004) Site-specific labelling with a metal chelator for protein-structure refinement. J. Biomol. NMR 29, 351-361.

(54) Soriano Del Amo, D., Wang, W., Jiang, H., Besanceney, C., Yan, A. C., Levy, M., Liu, Y., Marlow, F. L., and Wu, P. (2010) Biocompatible copper(I) catalysts for in vivo imaging of glycans. J. Am. Chem. Soc. 132, 16893-16899.

(55) Ilangovan, U., Ton-That, H., Iwahara, J., Schneewind, O., and Clubb, R. T. (2001) Structure of sortase, the transpeptidase that anchors proteins to the cell wall of Staphylococcus aureus. Proc. Natl. Acad. Sci. U.S.A. 98, 6056-6061.

(56) Liepinsh, E., Ilag, L. L., Otting, G., and Ibáñez, C. F. (1997) NMR structure of the death domain of the $\mathrm{p} 75$ neurotrophin receptor. EMBO J. 16, 4999-5005.

(57) Farkas, Ö., Salpietro, S. J., Császár, P., and Csizmadia, I. G. (1996) Conformations of ethylbenzene $\left(\mathrm{CH}_{3}-\mathrm{CH}_{2}-\mathrm{Ph}\right)$. An ab initio study. J. Mol. Struct. Theochem 367, 25-31.

(58) Prudêncio, M., Rohovec, J., Peters, J. A., Tocheva, E., Boulanger, M. J., Murphy, M. E. P., Hupkes, H. J., Koster, W., Impagliazzo, A., and Ubbink, M. (2004) A caged lanthanide complex as a paramagnetic shift agent for protein NMR. Chem.-Eur. J. 10, 3252-3260.

(59) Liu, C. C., and Schultz, P. G. (2010) Adding new chemistries to the genetic code. Annu. Rev. Biochem. 79, 413-444.

(60) Lee, H. S., Spraggon, G., Schultz, P. G., and Wang, F. (2009) Genetic incorporation of a metal-ion chelating amino acid into proteins as a biophysical probe. J. Am. Chem. Soc. 131, 2481-2483.

(61) Jones, D. H., Cellitti, S. E., Hao, X., Zhang, Q., Jahnz, M., Summerer, D., Schultz, P. G., Uno, T., and Geierstanger, J. (2010) Site-specific labeling of proteins with NMR-active unnatural amino acids. J. Biomol. NMR 46, 89-100.
(62) Xie, J., Liu, W., and Schultz, P. G. (2007) A genetically encoded bidentate, metal-binding amino acid. Angew. Chem., Int. Ed. 46, 92399242.

(63) Nguyen, T. H. D., Ozawa, K., Stanton-Cook, M., Barrow, R., Huber, T., and Otting, G. (2011) Generation of pseudocontact shifts in protein NMR spectra with a genetically encoded cobalt(II)-binding amino acid. Angew. Chem., Int. Ed. 50, 692-694. 